\title{
The Significance of Bragg's Law in Electron Diffraction and Microscopy and Bragg's Second Law
}

Colin Humphreys

University of Cambridge Bragg Symposium Adelaide 6 December 2012 


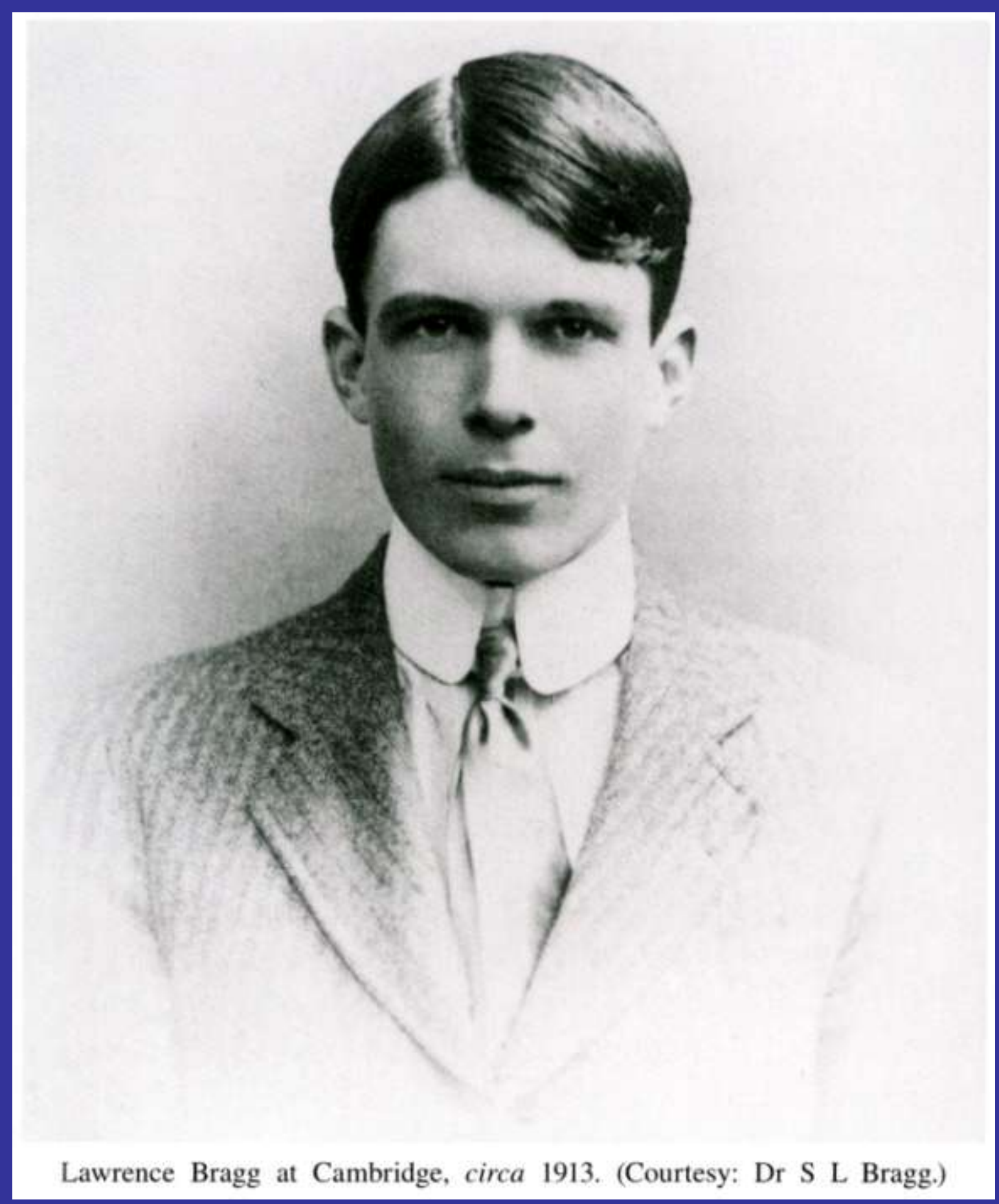




\section{Bragg's Second Law}

- E. W. Hughes: "How I first learned of the Patterson function and Bragg's second law"

- In Patterson and Pattersons: Fifty years of the Patterson function (IUCr, 1987)

- Lawrence Bragg visited Cornell in winter 1933

- Streets sheets of ice

- Hughes driving Bragg in Model A Ford

- Bragg describing the Patterson method 


\section{Bragg's Second Law (2)}

- Bragg used the fingers of one hand to describe atomic position vectors

- Those of the other hand to represent their differences

- Hughes forgot all about the ice

- Red traffic light ahead at a road junction

- Hughes braked, skidded, swerved and crossed the red light: in the path of a heavy lorry going fast through its green light. Lorry swerved and missed them by foot. 


\section{Bragg's Second Law (3)}

- Hughes, shaken and stirred, cautiously drove on

- "Though all this, Bragg continued to wave his hands and lecture on Patterson's vectors, but to a deaf audience!"

- Following year, Hughes in England, Bragg driving him. Passed the scene of a recent terrible road accident. Reminded Hughes of the Ithaca incident. Hughes asked Bragg if he remembered. Bragg "Indeed I do". He then stated the following, which Hughes calls Bragg's second law. 


\section{Bragg's Second Law}

"When travelling in a foreign country I make it a point of personal honour not to show fear, anger, or mirth, or surprise at any happening that does not seem to be unusual to the natives." 
Electron and X-ray diffraction: similarities and differences. Example: the Critical Voltage effect

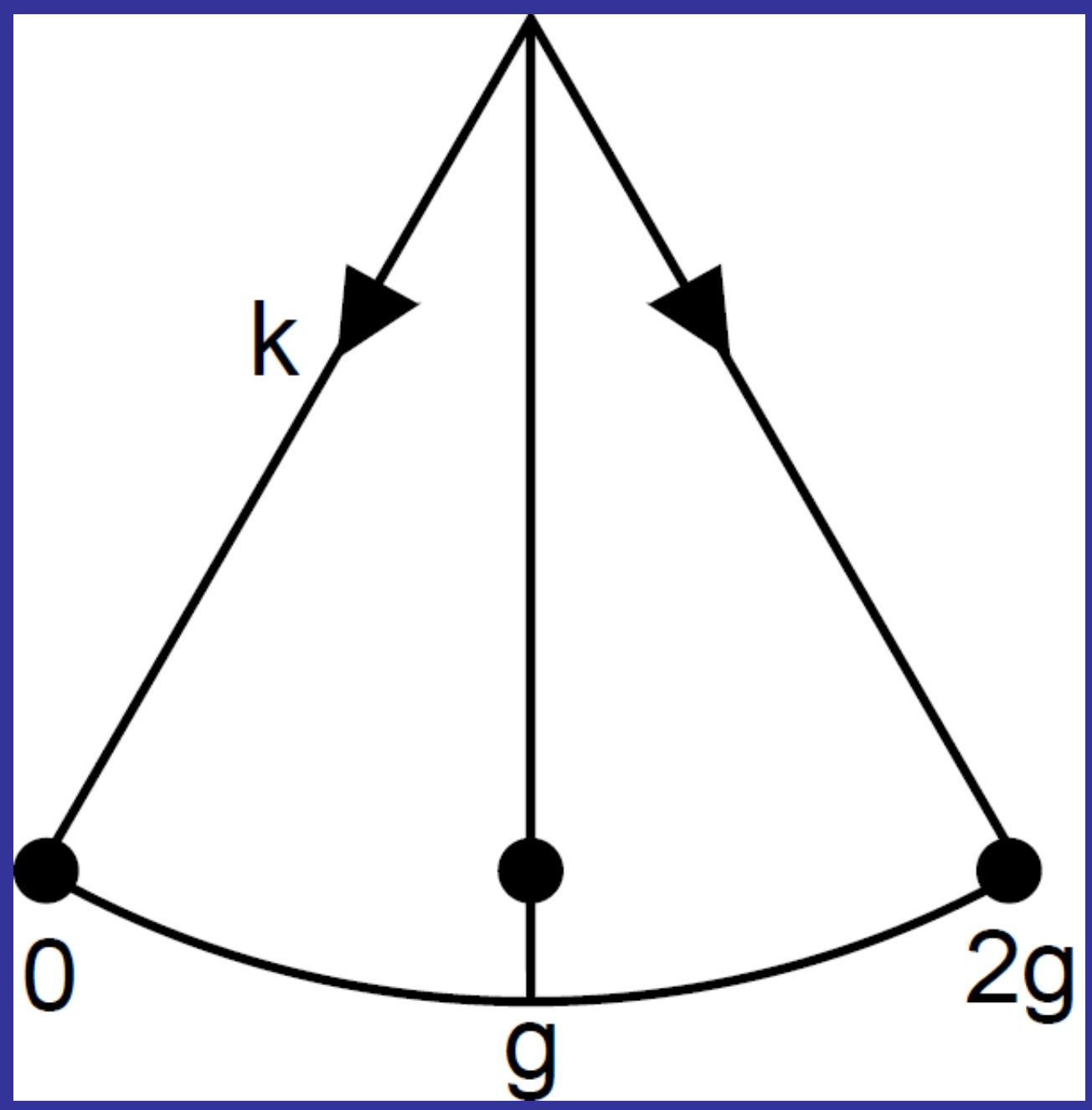




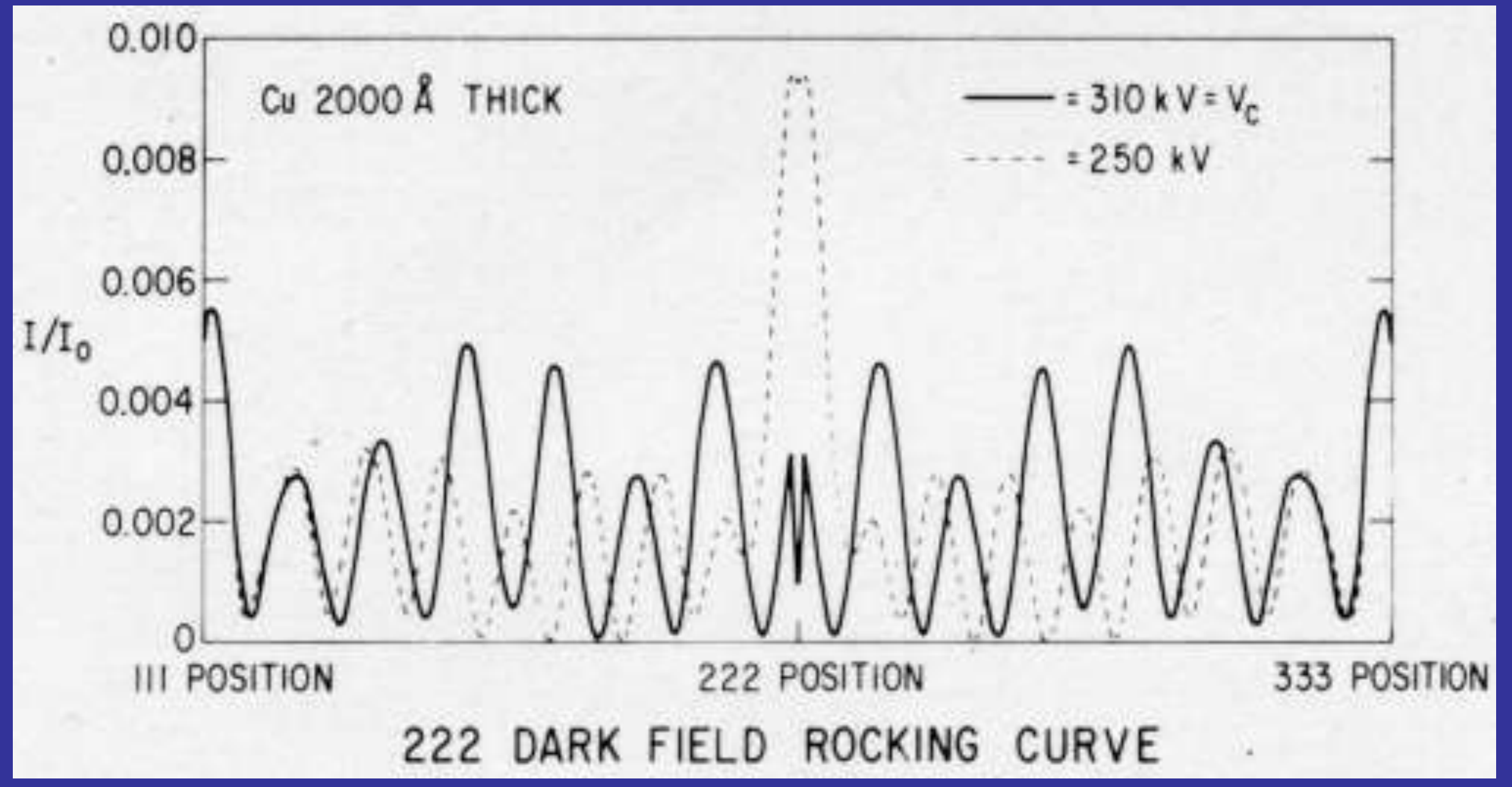

Calculated 222 dark-field rocking curves for incident accelerating voltages of $250 \mathrm{kV}$ and $310 \mathrm{kV}$, the critical voltage. Can measure $\mathrm{V}(\mathrm{g}), \mathrm{F}(\mathrm{g})$, $\mathrm{f}(\mathrm{g})$ very accurately(Lally et al., 1972) 


\section{Bragg's law and the electron microscope}

imaging of lattice planes in crystals

- Bragg's real-space vision was that X-rays are reflected from lattice planes in crystals

- In electron microscopy, the electron wavefunction in the image plane is the FT of that in the diffraction plane, which is the FT of the wavefunction on the exit surface of the crystal

- Hence, the electron microscope image of a crystal directly reveals the Bragg planes used for the imaging process

- Example, InGaN/GaN quantum wells in LEDs 


\section{GaN}

InGaN
High-resolution TEM (0002) lattice fringe image of three InGaN quantum wells separated by GaN barriers. Beams 0 and 0002 were used to form the image.

Can directly measure the thicknesses of the quantum wells and the barriers (cf Xrays) 


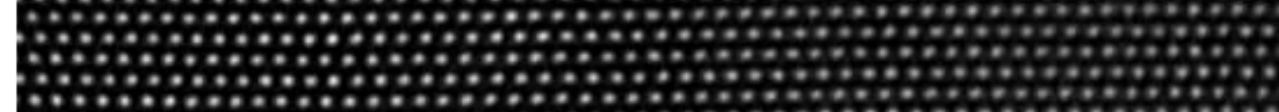

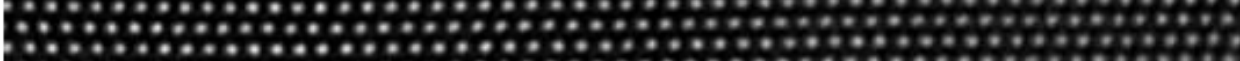

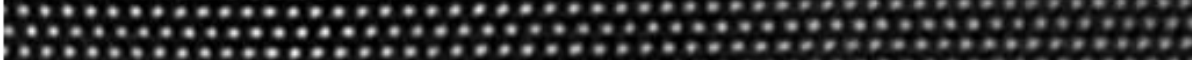

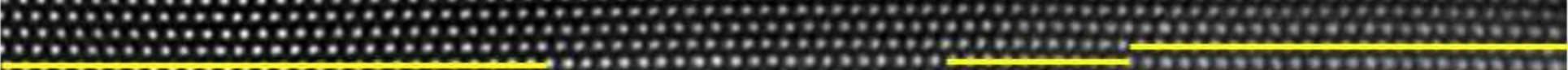

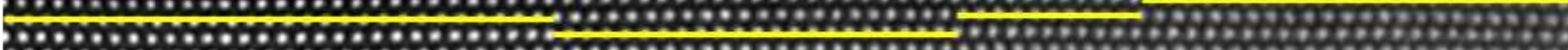

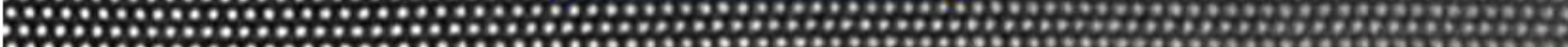

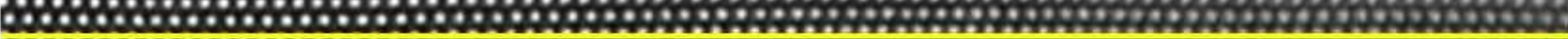

$\therefore$

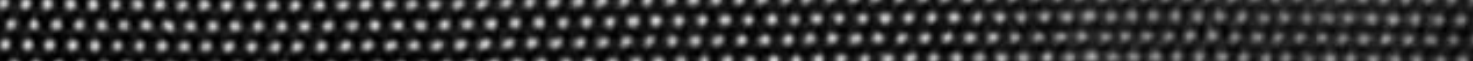

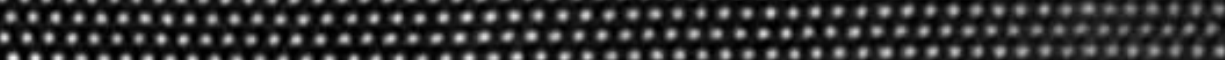

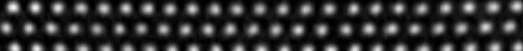

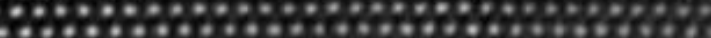


. 

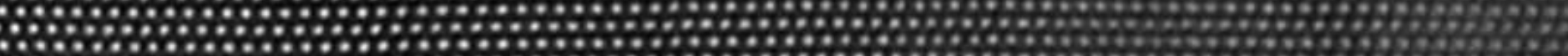

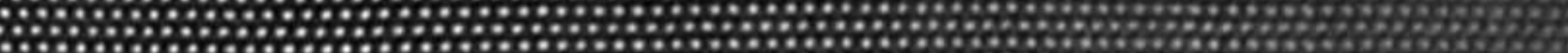
\%on 

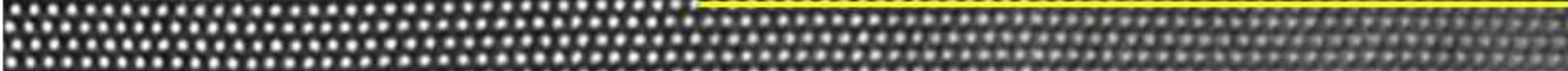

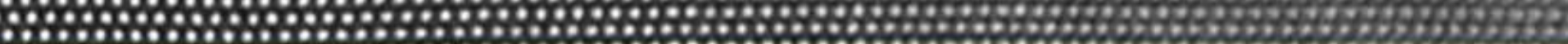

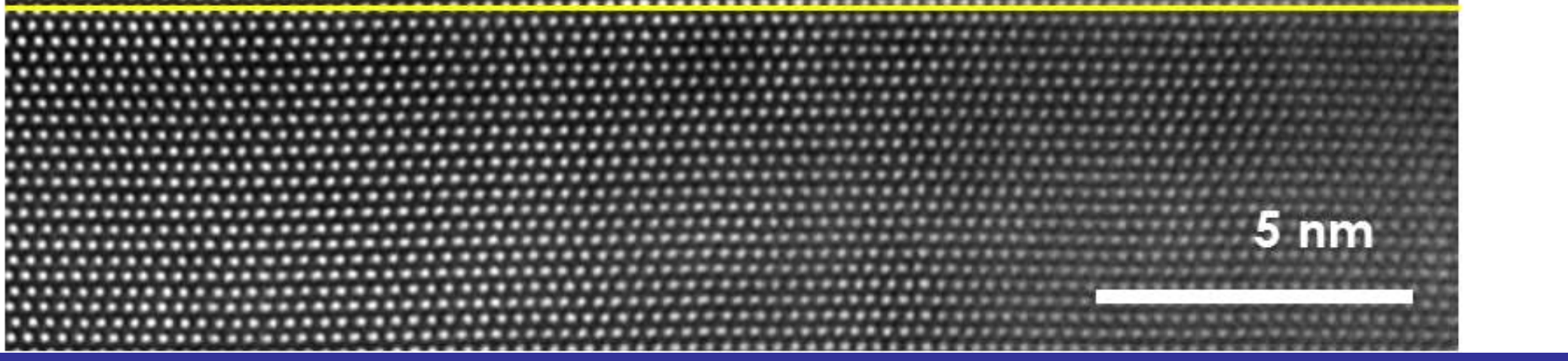

InGaN

GaN

InGaN 


\section{The InGaN LED mystery}

- High densities of threading dislocations $\left(\sim 10^{9} \mathrm{~cm}^{-2}\right)$.

- Threading dislocations may be shown (e.g. by CL) to act as non-radiative recombination centres.

- For efficient light emission, dislocation densities should be less than $\sim 10^{3} \mathrm{~cm}^{-2}$ in GaAs and other III-V semiconductors.

- Some microstructural feature of the InGaN QW appears to prevent the carriers from reaching the dislocation cores.

- Interface steps, revealed by TEM, are a key localisation mechanism 


\section{A quantum well with a step}

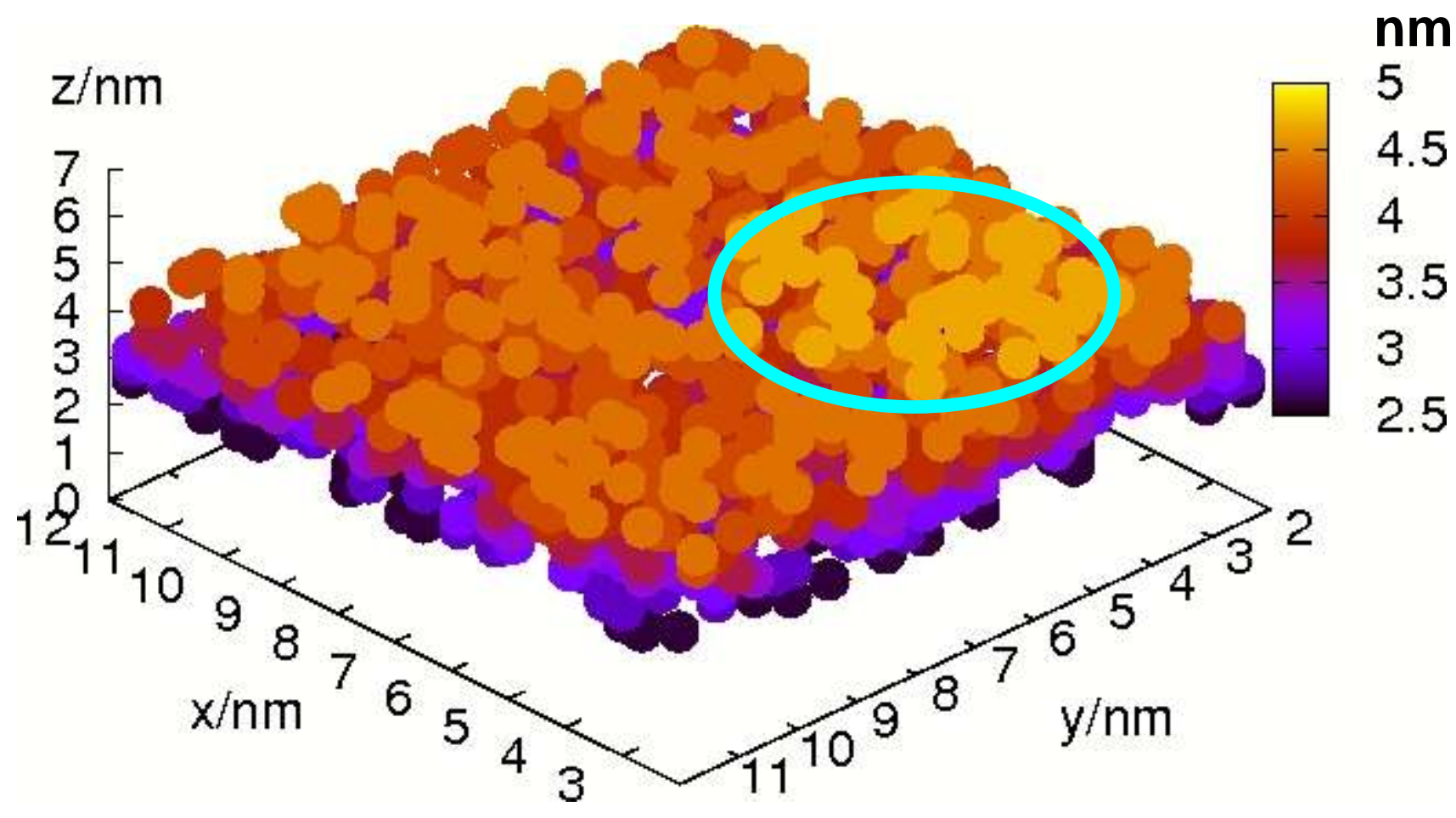

- A single monolayer island is added to the random quantum well - as seen in the atom probe and TEM data. 


\section{Electron and hole wavefunctions (1)}

$\psi^{2} \mathrm{e}$

Electron

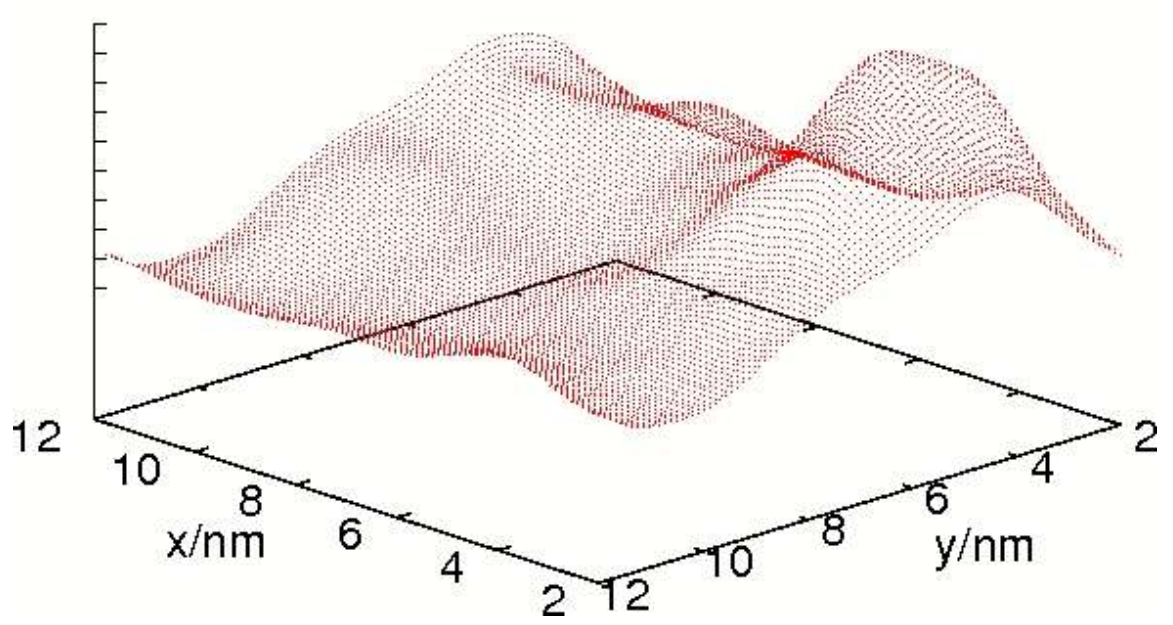

$$
\psi_{\mathrm{h}}^{2} \quad \text { Hole }
$$

12

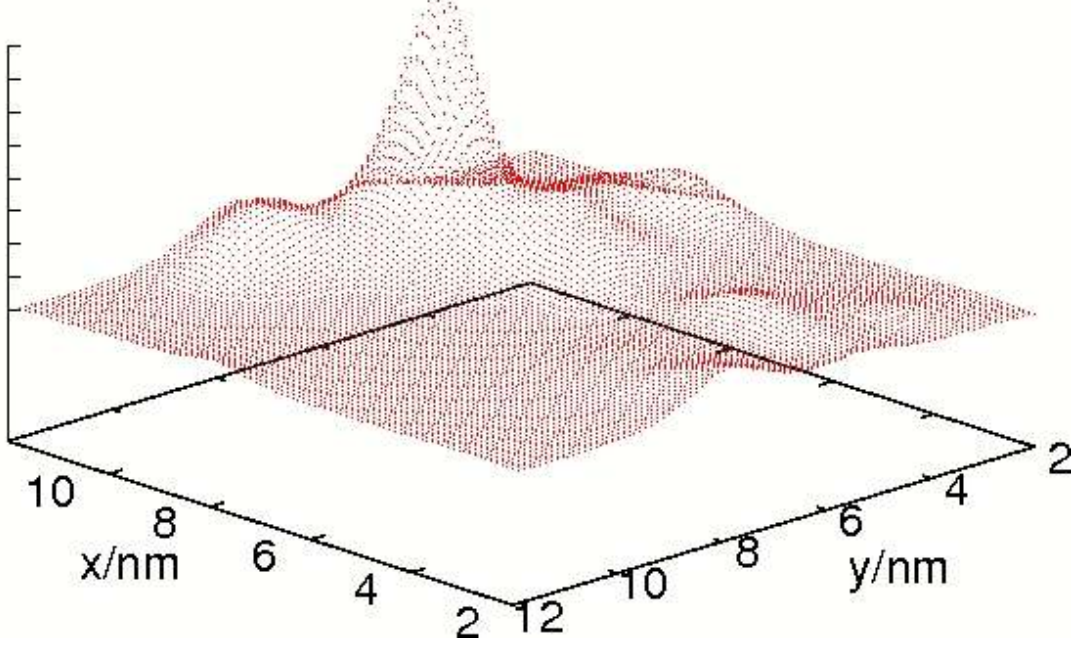

- The electron and hole are most likely to be found where the square of the wavefunction is highest.

- The electron and hole are localised at different positions.

- Localisation length: electron $\sim 4 \mathrm{~nm}$, hole $\sim 1 \mathrm{~nm}$ 


\section{Key points from modelling}

- Carrier diffusion to dislocations is prevented even in the absence of gross indium clusters.

- Even in a random InGaN quantum well, areas of higher indium content exist.

- Random alloy fluctuations localise the holes (localisation energy about $20 \mathrm{meV}$ )

- Monolayer steps localise the electrons (localisation energy about $28 \mathrm{meV}$ )

(15) Cambridge Centre for GALliUM NitRIDE 


\section{Bragg's law and the absence of Bragg reflecting planes}

- Often have thin amorphous regions at interfaces

- No Bragg reflecting planes

- Can be difficult to detect using X-rays

- Can be detected using electron microscopy

- Can be chemically analysed in an electron microscope 


\section{AIN on Si: nature of the AIN/Si interface}

Sample growth :

$200 \mathrm{~nm}$ layer of AIN on Si (111)

TMA predose

Growth temperature $1160^{\circ} \mathrm{C}$ $1100^{\circ} \mathrm{C}$

$1130^{\circ} \mathrm{C}$

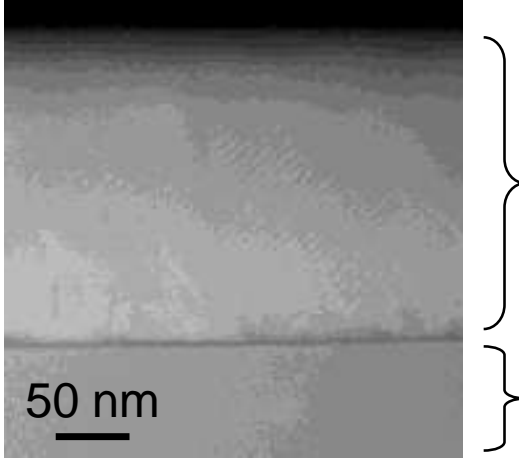

200nm AIN layer

$\mathrm{Si}(111)$ substrate

Sample preparation :

Cross-section Si [110]

Mechanical polishing - $2^{\circ}$ wedge

Gentle mill (10 min. @ 300 eV; 10min. @ 150 eV)

Microscope :

Titan 80-300 cubed TEM

image and probe Cs-correctors monochromator

high brightness XFEG gun

Gatan 866 Tridiem energy filter
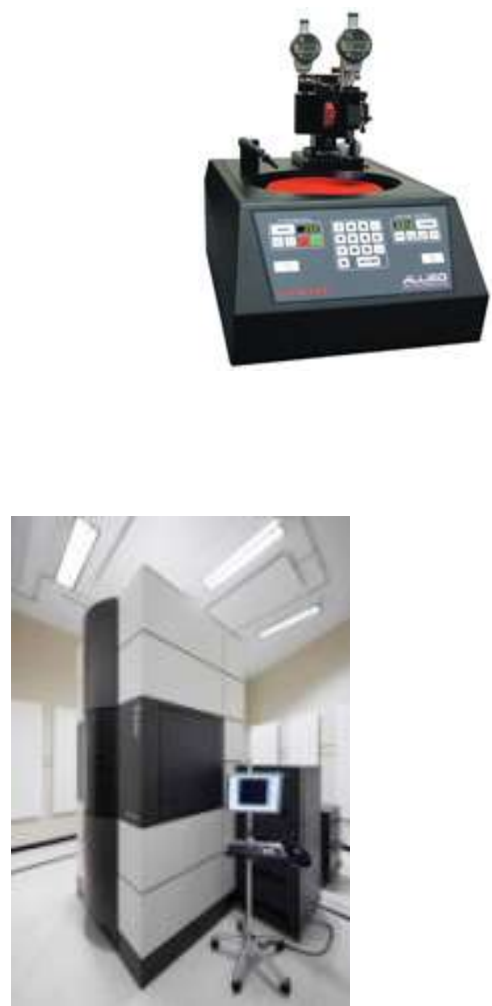


\section{HAADF Imaging - Cs corrected Titan 80-300}

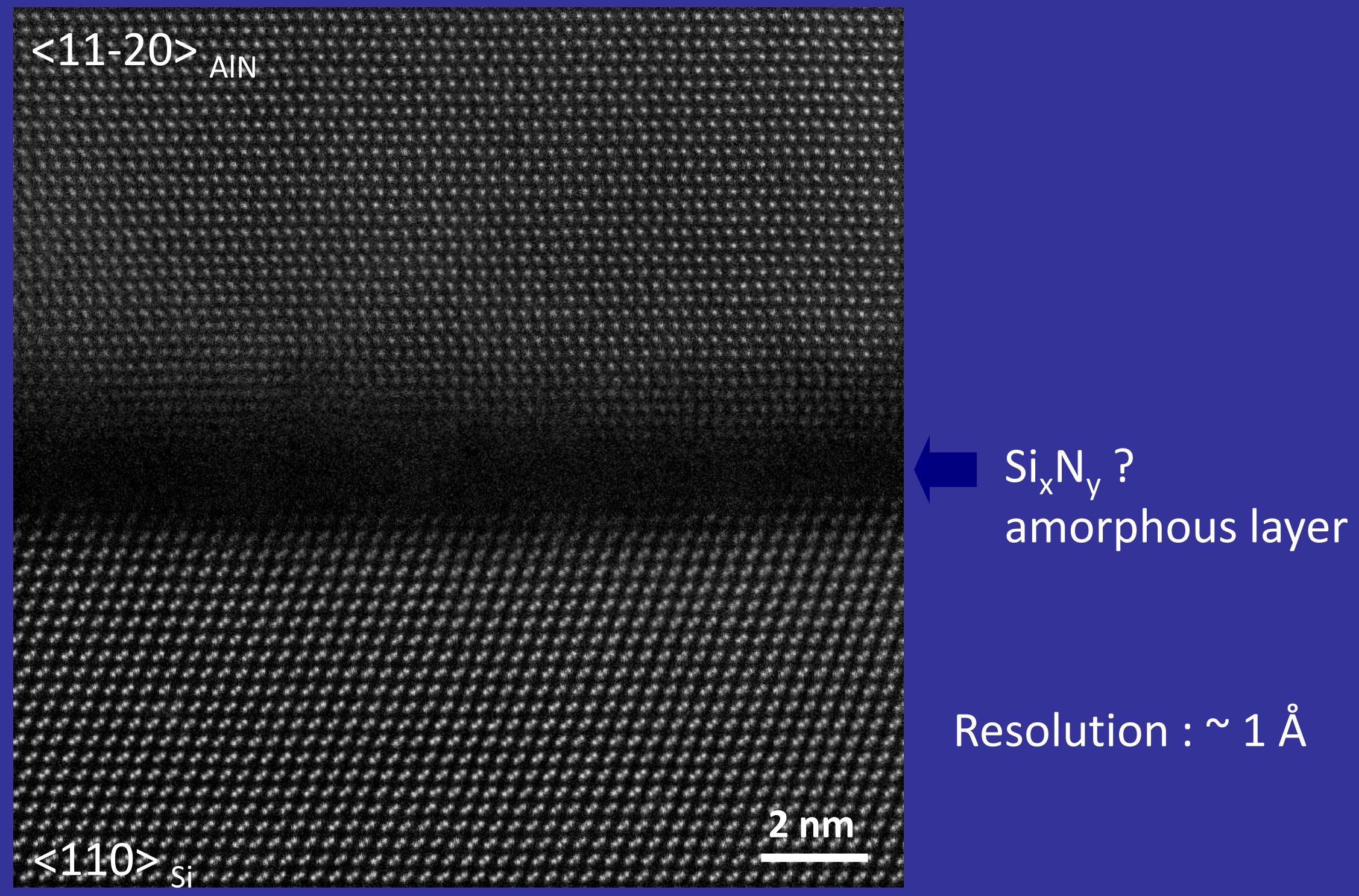




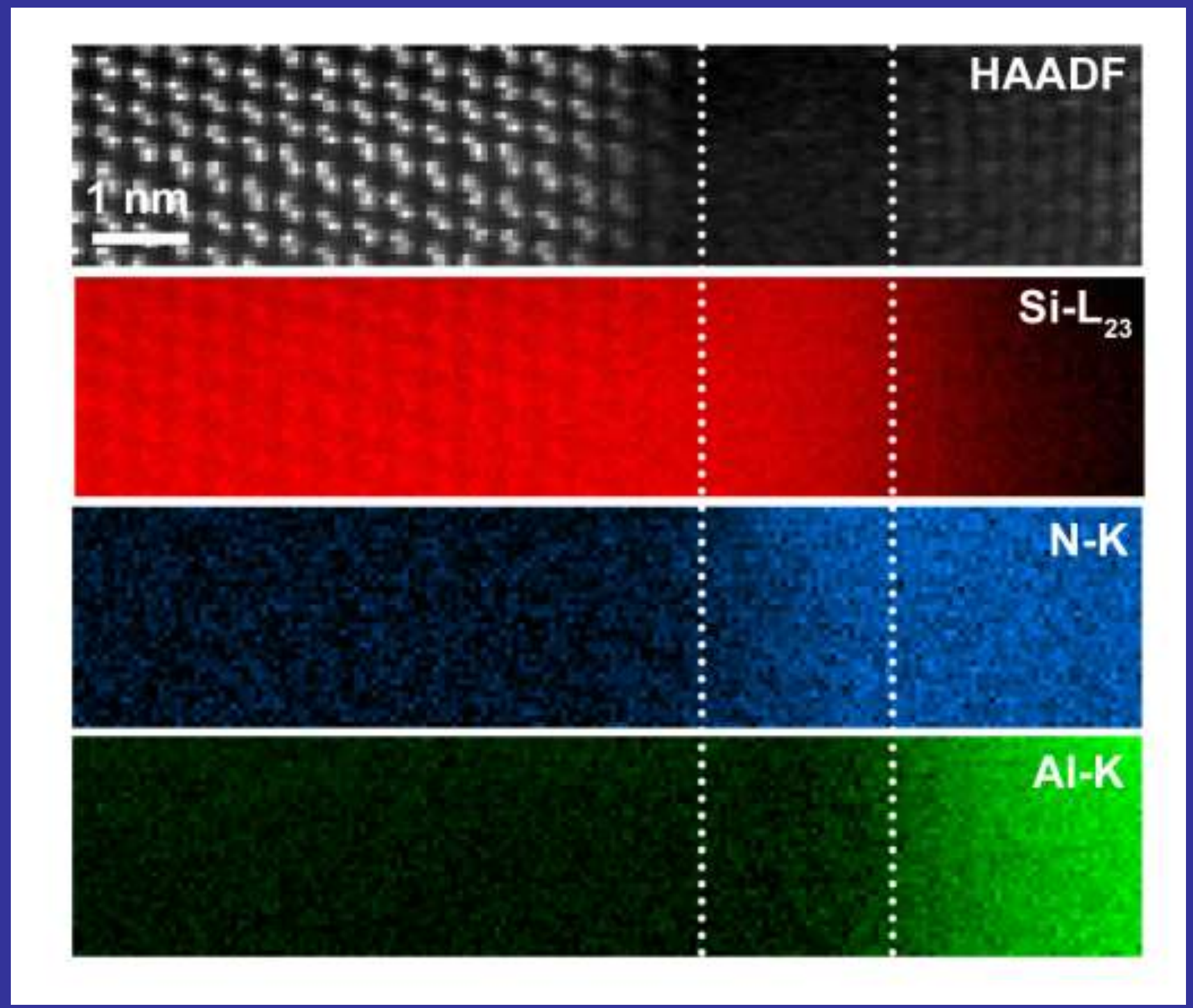

Dotted lines show position of the amorphous layer. EELS spectral images show amorphous layer is $\mathrm{Si}_{x} \mathrm{~N}_{y}$ 


\section{Imaging and identifying single atoms using $\mathrm{X}$-rays}

- Developments in X-ray instrumentation in 2012 enable single atoms to be imaged and identified using $\mathrm{X}$-rays

- Single-atom X-ray analysis made possible by 0.1 $\mathrm{nm}$ diameter electron beams, FEG sources, windowless EDX with silicon drift detectors

- Bragg would have been amazed and delighted! 
Simultaneous identification of a single atom by EELS and EDX (Suenaga et al., Nature Photonics , 2012)

(a)

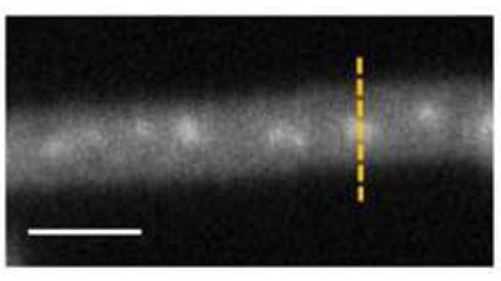

(b)

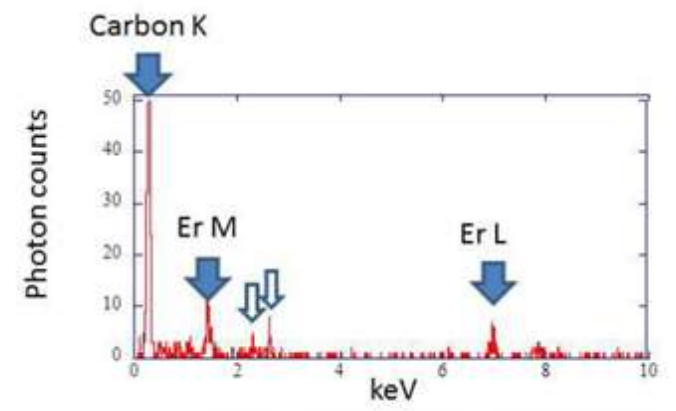

(c)

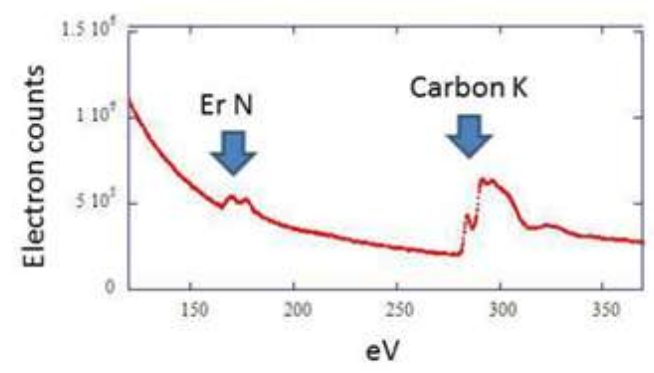




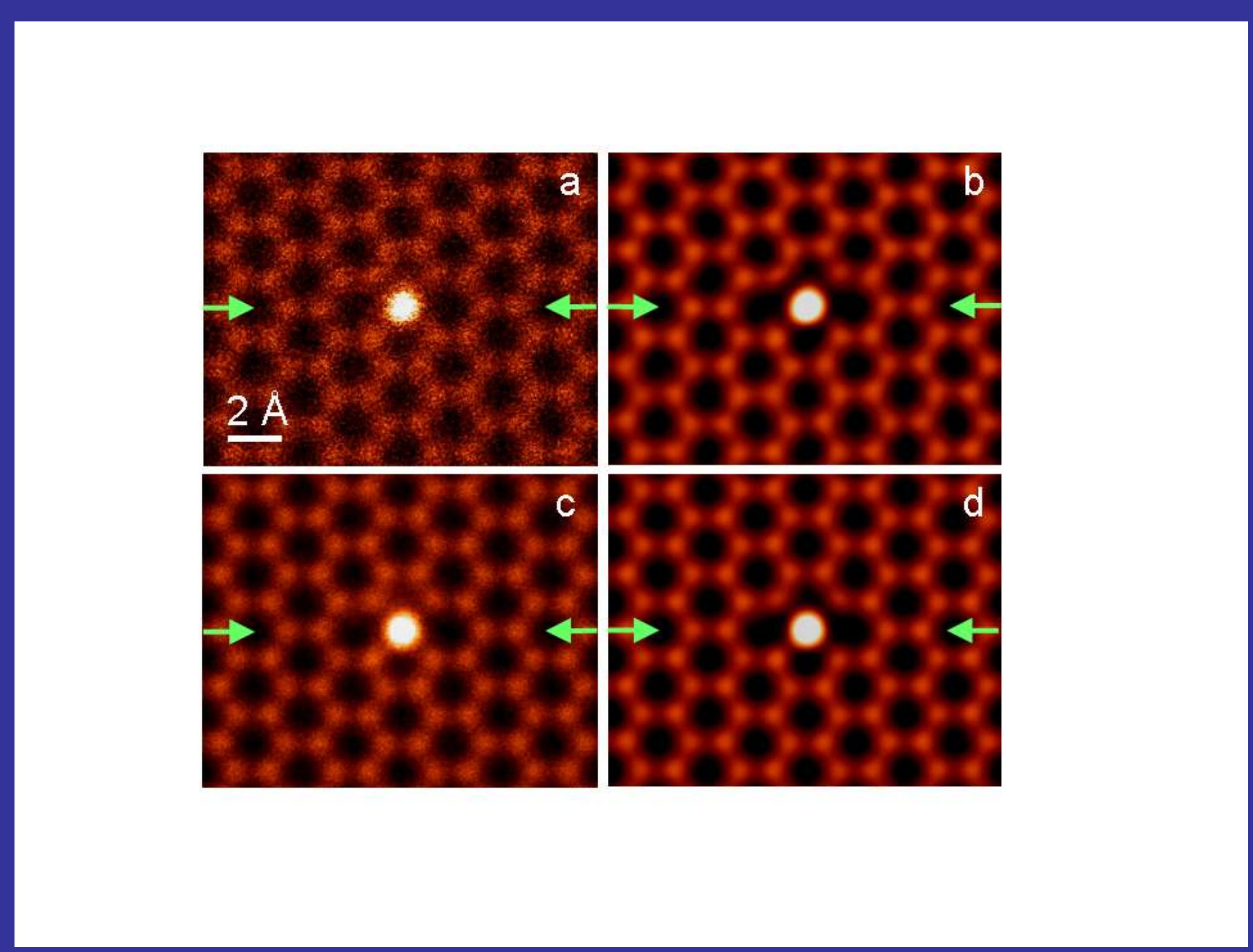

A single Si atom in a graphene monolayer. HAADF-STEM image. NION UltraStem. Impurity atom identified as Si using simultaneous EDX and EELS. 4 mins, 60 keV electrons. (Lovejoy et al., APL, 2012) 
Atomic resolution X-ray maps (EDX in an EM) of GaAs. (JEOL Centurio, 2012). Note chess-board pattern of atoms.
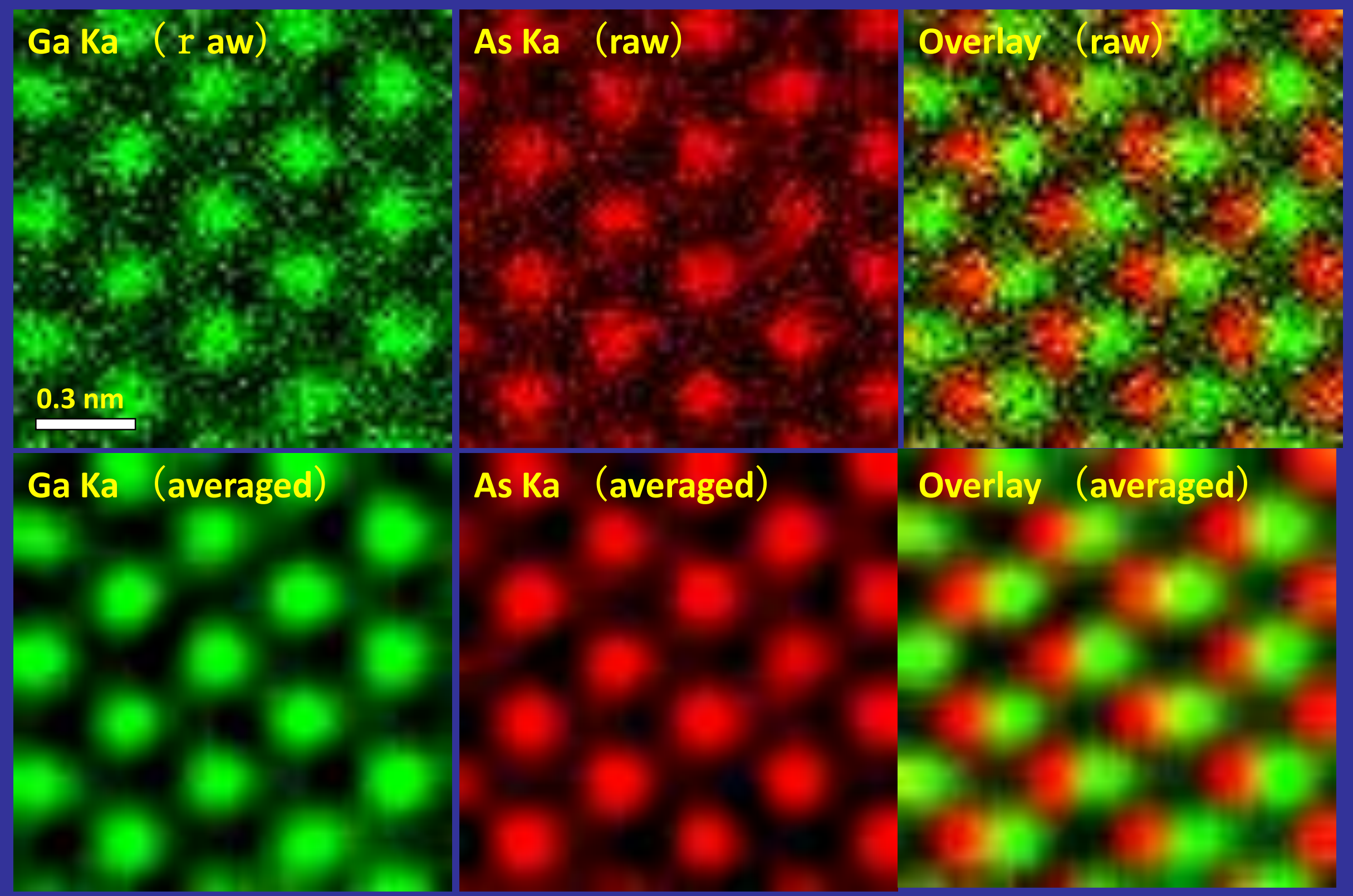


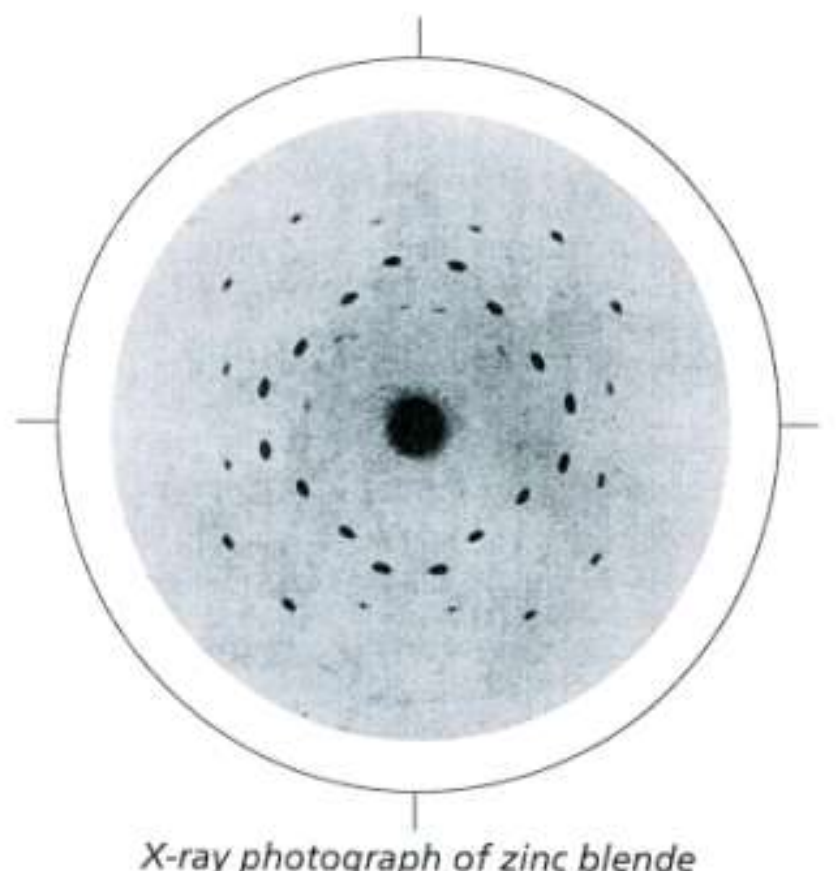

X-ray photograph of zinc blende

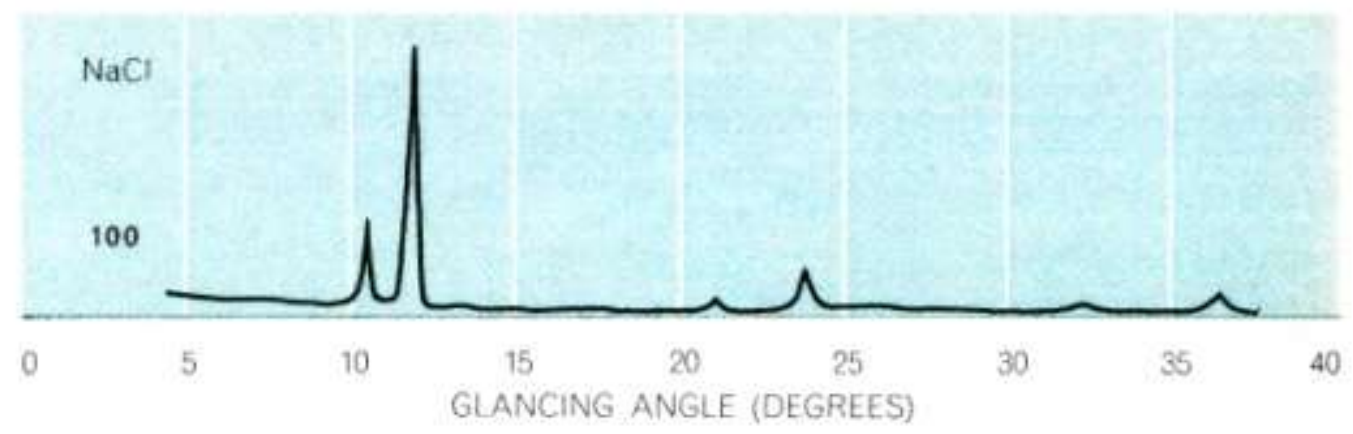

GLANCING ANGLE (DEGREES)
Figure 1 One of the X-ray photographs of zinc blende ( $\mathrm{ZnS}$ ) published by Friedrich, Knipping and Laue in $1912^{\prime}$.
Example of an early measurement by Lawrence Bragg, using the $\mathrm{X}$-ray spectrometer devised by his father. The incident $X$-rays impinge upon the cleavage face of rock salt ( $\mathrm{NaCl})$. The two peaks seen in each order $(n=1,2$, etc according to Bragg's law) arise from the $\mathrm{K}_{\mathrm{a}}$ and $\mathrm{K}_{\mathrm{p}}$ "lines" in the spectrum of the palladium anticathode used to generate the monochromatic $\mathrm{X}$-rays. 


\section{Letter to Nature in1927 by H E Armstrong}

- "Prof W. L. Bragg asserts that 'In sodium chloride there appear to be no molecules represented by $\mathrm{NaCl}$. The equality in number of sodium and chlorine atoms is arrived at by a chess-board pattern of these atoms."'

- "This statement is more than repugnant to common sense. It is absurd to the $n$. .. $^{\text {th }}$ degree."

- "Chemistry is not chess, whatever X-ray physics may be... It is time that chemists took charge of chemistry once more." 


\section{Atomic resolution $X$-ray maps (using EDX in an EM) of}

GaAs. (JEOL Centurio). Note chess-board pattern of atoms.

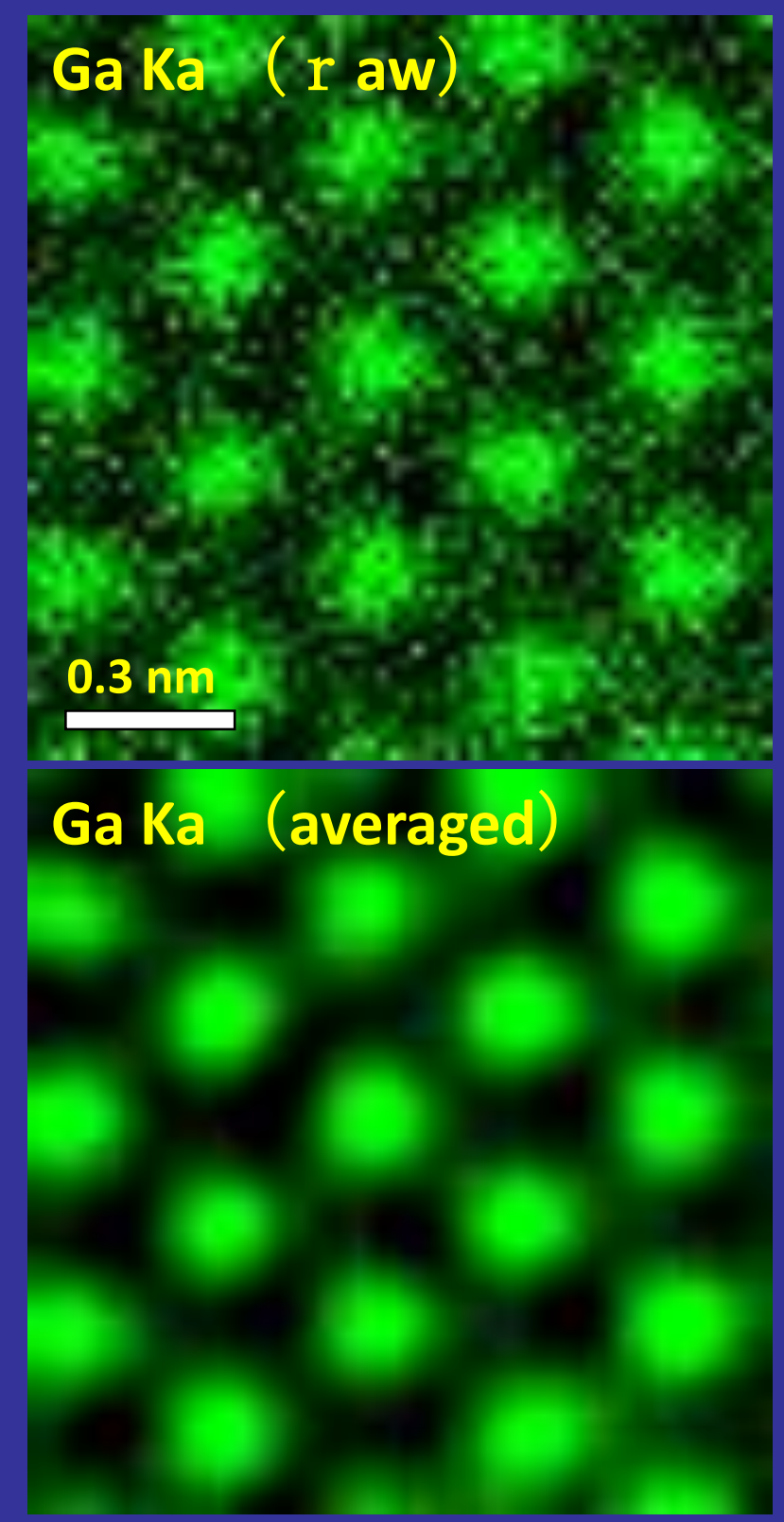

As Ka (raw)

As Ka (averaged)
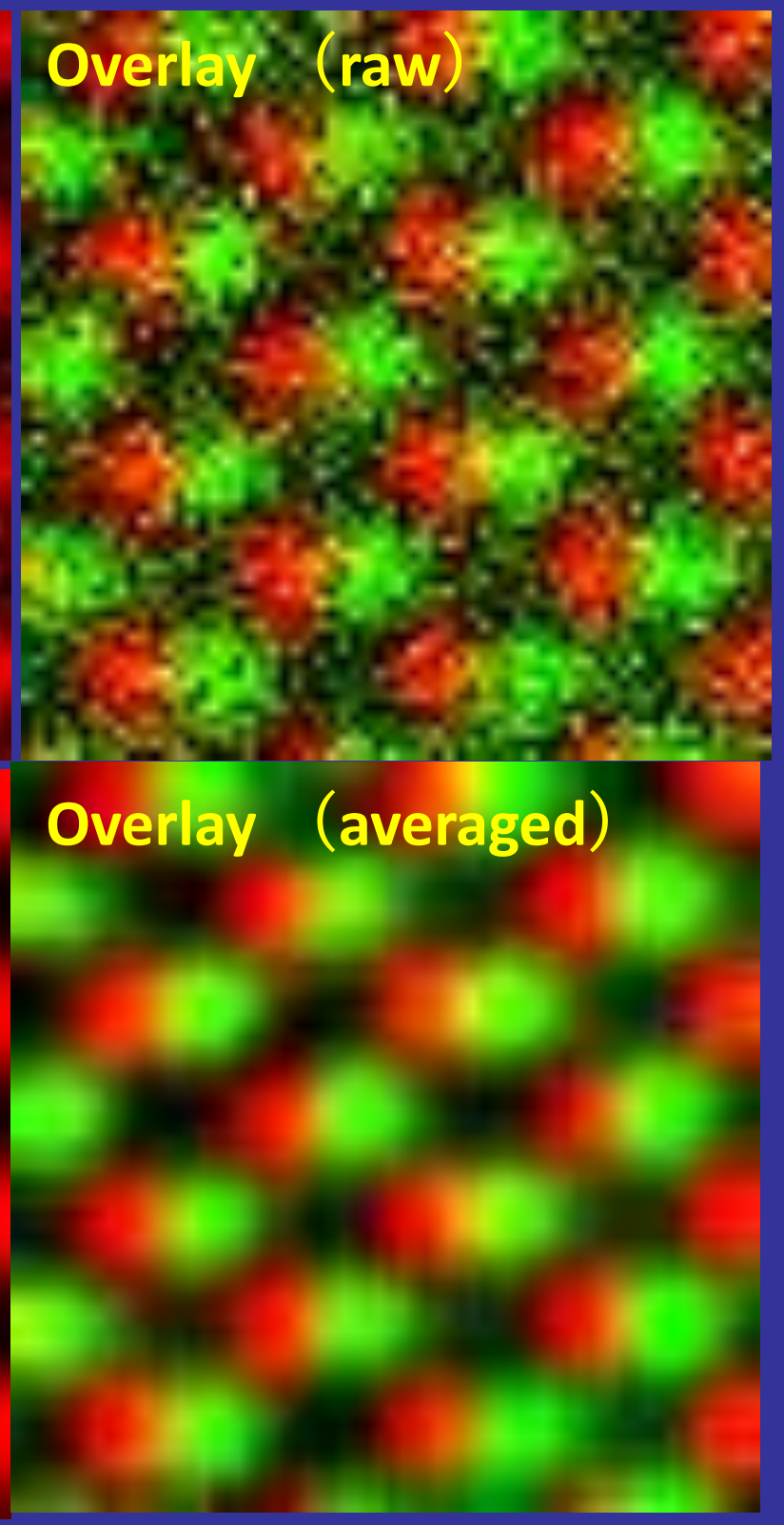


\section{Bragg: 100 years on}

- One hundred years later, Bragg's real-space vision of using X-rays to determine crystal structures is now being realised in a way he could not gave imagined, but in a way he would surely have approved 


\section{Bragg: Crystals and Gems}

- 1959 TV series: "The Nature of Things"

- TV series for children

- Live audience at the Royal Institution

- "Crystals and Gems" one episode in the series

- Lawrence Bragg to Bill Coates: "Never talk about science, show it to them" 